\title{
KEMANUSIAAN-SUBSTITUSIONAL KRISTUS DALAM PEMIKIRAN THOMAS F. TORRANCE
}

\section{Yeremia Yordani Putra*}

\begin{abstract}
This paper focuses on Thomas F. Torrance's thought on the Vicarious Humanity of Christ. Torrance understands that the redemptive work of Christ is not restricted to the moment of His death on the cross, but is in all moments of His human life. Torrance places great emphasis on the understanding that Christ in His humanity stands in our place and represents us before God the Father. Through His obedience, Christ restored the humanity of sinful believers as a perfect response to God. This truth stresses that Christ's redemption is not just a matter of the forgiveness of sins, but also is the bestowing of a restorative impact on the whole being of the believers. Therefore, the Vicarious Humanity of Christ becomes the ontological basis for the life of the believers. This thought gives great significance to the lives of believers, including the aspects of faith, repentance, and worship.
\end{abstract}

Keywords: The Vicarious Humanity of Christ, Fallen Humanity, Perfect Response, Thomas F. Torrance.

Abstrak: Tulisan ini menyoroti pemikiran Thomas F. Torrance mengenai Kemanusiaan-Substitusional Kristus. Torrance memahami karya penebusan Kristus bukan hanya dibatasi pada momen kematian-Nya di atas kayu salib, melainkan dalam seluruh momen kehidupan-Nya sebagai manusia. Torrance sangat menekankan pemahaman bahwa Kristus dalam kemanusiaan-Nya berdiri di tempat kita dan mewakili kita di hadapan Allah Bapa. Melalui ketaatan-Nya, Kristus memulihkan kemanusiaan orang percaya yang

* Penulis adalah mahasiswa Pascasarjana STT Amanat Agung. Penulis dapat dihubungi melalui email: yeremiaputra35@gmail.com. 
telah berdosa sebagai respons sempurna kepada Allah. Kebenaran ini menegaskan bahwa penebusan Kristus bukan hanya soal pengampunan dosa, tetapi juga penganugerahan dampak restoratif pada seluruh keberadaan diri orang percaya. Oleh karena itu, Kemanusiaan-Substitusional Kristus menjadi dasar ontologis bagi kehidupan orang percaya. Pemikiran ini memberikan signifikansi yang besar bagi kehidupan orang percaya, di antaranya dalam aspek iman, pertobatan, dan ibadah.

Kata-kata kunci: Kemanusiaan-Substitusional Kristus, Kemanusiaan Berdosa, Respons Sempurna, Thomas F. Torrance

\section{Pendahuluan}

Salah satu doktrin krusial dalam iman Kristen adalah doktrin mengenai penebusan Kristus, oleh karena di dalam dan melalui realitas tersebut keselamatan bagi manusia yang berdosa menjadi mungkin. Akan tetapi, seperti yang dikatakan David W. Torrance, pengertian tentang tindakan substitusi Kristus dalam karya penebusan-Nya bagi manusia seringkali dipersempit hanya pada momen kematian-Nya semata. ${ }^{1}$ Tentu saja hal ini akan membuat gambaran tentang penebusan Kristus menjadi kurang utuh. Thomas Forsyth Torrance merupakan salah satu teolog yang berupaya memperluas pemahaman yang sempit terhadap penebusan Kristus tersebut. Torrance menegaskan bahwa signifikansi penebusan bagi kehidupan orang percaya terjadi bukan hanya pada peristiwa kematian Kristus saja, tetapi di dalam keseluruhan kemanusiaan-Nya

1. David W. Torrance, "The Vicarious Humanity of Christ" (makalah ini disampaikan pada konferensi teologi T. F. Torrance yang diadakan pada November 2010 di Firbush, Loch Tay, Universitas Edinburgh). 
(kehidupan, kematian, kebangkitan, dan kenaikan-Nya). Karena menurut Torrance, kemanusiaan Kristus merupakan aspek yang integral dan esensial dari karya penebusan Allah, di mana segala kekayaan Allah dalam Kristus dapat menjadi bagian yang nyata dalam kemanusiaan orang percaya. Perspektif seperti ini akan menepis pemahaman bahwa kemanusiaan Kristus hanya sebagai instrumental, ${ }^{2}$ sehingga penebusan Kristus hanya dilihat sebagai "sesuatu yang mengena di kepala kita," alih-alih "sebagai sesuatu yang berdampak pada kedalaman keberadaan kita yang sebenarnya melalui kesatuan yang dikerjakan oleh Kristus dengan mengikutsertakan kita dalam kemanusiaan substitusional-Nya." ${ }^{3}$

Tulisan ini berupaya untuk menggali lebih dalam doktrin Kemanusiaan-Substitusional Kristus (the Vicarious Humanity of Christ) menurut Torrance. Pokok pembahasan yang akan disoroti adalah tentang bagaimana doktrin tersebut memberikan dampak bagi kehidupan orang percaya. Dalam hal ini, tiga aspek kehidupan orang percaya akan diangkat dalam pembahasan, yaitu iman, pertobatan, dan ibadah. Bertolak dari sana, maka KemanusiaanSubstitusional Kristus dapat dihayati sebagai dasar ontologis kehidupan iman orang percaya dan respons mereka kepada Allah.

2. Paul D. Monar, Thomas F. Torrance: Theologian of the Trinity (England: Ashgate Publishing, 2009), 119. Kritik Torrance tentang inkarnasiinstrumental dapat lihat Thomas F. Torrance, The Trinitarian Faith: The Evangelical Theology of Ancient Catholic Church (London: T \& T Clark, 1988), 119.

3. Monar, Thomas F. Torrance: Theologian of the Trinity, 119. 


\section{Kemanusiaan-Substitusional Kristus}

Pada bagian ini, penulis akan memetakan pemikiran Torrance mengenai Kemanusiaan-Substitusional Kristus dalam dua pembahasan, yaitu (1) Prakondisi Kemanusiaan-Substitusional Kristus, (2) Kemanusiaan Kristus sebagai Respons Sempurna kepada Allah.

\section{a. Prakondisi Kemanusiaan-Substitusional Kristus}

Mengikuti keyakinan Gregorius dari Naziansus, Torrance menegaskan bahwa jika Yesus Kristus tidak mengambil daging yang jatuh (fallen flesh), kemanusiaan yang berdosa, maka manusia yang berdosa tidak tersentuh oleh karya-Nya. ${ }^{4}$ Menurut Torrance, Kristus tidak mengambil kemanusiaan pra-kejatuhan, sebaliknya Kristus mengambil kemanusiaan yang telah jatuh (The assumption of fallen flesh). ${ }^{5}$ Seperti yang disaksikan oleh Rasul Yohanes dalam Injil Yohanes 1:14a, "Firman menjadi daging (flesh),.." di mana kata "daging" memberikan penekanan bahwa Firman Allah sepenuhnya berpartisipasi di dalam natur dan keberadaan manusia yang telah jatuh dalam dosa. Hal ini dijelaskan oleh Torrance dalam bukunya The Doctrine of Jesus Christ, bahwa kata "daging" dalam Perjanjian Baru menunjukkan manusia yang jatuh di bawah murka Allah dan

4. Torrance F. Torrance, Incarnation: The Person and Life of Christ, ed., Robert T. Walker (Downers Grove: InterVarsity Press, 2008), 62.

5. Torrance, Incarnation, ed., Robert T. Walker, 61. 
membutuhkan penebusan dan pendamaian dengan Allah. ${ }^{6}$ Kepada kemanusiaan inilah Allah menaruh belas kasihan-Nya yang besar, sehingga Dia merendahkan diri-Nya dan benar-benar turun ke dalam dunia. Melalui kelahiran-Nya dari perawan Maria, Kristus menjadi manusia. Hal ini berarti bahwa daging yang Dia ambil tidak dalam arti netral, tetapi sebagai benar-benar daging kita yang telah jatuh. ${ }^{7}$

Menurut Torrance, hal ini dapat dilihat dengan jelas pada peristiwa baptisan Kristus, di mana Dia mengidentifikasikan diri-Nya dengan manusia berdosa dengan cara dibaptis dengan baptisan pertobatan, ${ }^{8}$ dan setelah itu Dia dituntun oleh Roh Kudus menuju ke padang gurun selama empat puluh hari berpuasa dan dicobai seperti halnya manusia lainnya yang mengalami pencobaan. Sebagai manusia, Kristus pun dapat mengalami penderitaan, kelemahan, kelaparan, bahkan kehausan. Sampai di penghujung kehidupan-Nya, Kristus mengalami puncak penderitaan sebagai manusia. Torrance menggambarkan apa yang terjadi pada Kristus di Getsemani sebagai tindakan substitusi dengan meminum ampas cangkir penghakiman ilahi atas dosa kita, sehingga Dia berseru dalam derita-Nya, "Eli, Eli Lama sabachthani." ${ }^{\prime 9}$

Kendatipun Kristus mengambil kemanusiaan yang berdosa, Kristus tidak menjadi berdosa. Seperti yang dikatakan Torrance

6. Thomas F. Torrance, The Doctrine of Jesus Christ (Eugene: Wipf and Stock Publishers, 2002), 121.

7. Torrance, The Doctrine of Jesus Christ, 121.

8. Torrance, Incarnation, ed., Robert T. Walker, 62.

9. Torrance, The Doctrine of Jesus Christ, 122. 
dengan jelas dalam pernyataannya, bahwa Yesus bukanlah orang yang berdosa, tetapi Dia memasuki wilayah yang telah jatuh dan mengidentifikasi diri-Nya dengan setiap manusia dalam dosa mereka, dan berada di bawah kutukan hukum. ${ }^{10}$ Torrance menjelaskan ketegangan ini dengan hubungan yang dinamis antara tindakan pengambilan (assumption) dan tindakan pengudusan (sanctification) dalam diri Kristus. Torrance menjelaskan dari sudut pandang tindakan pengudusan Allah terhadap daging yang telah jatuh (the sanctification of fallen flesh). la mengatakan bahwa sementara Firman mengambil daging yang telah jatuh, Firman juga menguduskan dan menyucikannya, karena pengambilan daging kita yang berdosa itu sendiri adalah tindakan penebusan dan pengudusan. ${ }^{11}$ Di satu sisi, Kristus benar-benar seperti manusia berdosa (like us), dalam semua hal, dalam kemanusiaan yang lemah, rusak serta dapat tergoda. ${ }^{12}$ Kristus sepenuhnya menyatu dengan kemanusiaan yang berdosa. Tetapi di sisi lain, Kristus benar-benar tidak seperti manusia berdosa (unlike us), karena Kristus bukan hanya mengambil sifat manusia yang berdosa bagi diri-Nya sendiri melainkan juga menguduskannya. ${ }^{13}$ Torrance mengatakan, "Sang Anak sepenuhnya seperti kita, dalam hal Dia menjadi seperti kita, tetapi juga sepenuhnya tidak seperti kita, dalam hal la menolak dosa

10. Torrance, The Doctrine of Jesus Christ, 121.

11. Torrance, Incarnation, ed., Robert T. Walker, 63.

12. Torrance, Incarnation, ed., Robert T. Walker, 205.

13. Torrance, Incarnation, ed., Robert T. Walker, 205. 
kita, dan hidup dalam ketaatan yang penuh dan sempurna kepada Bapa."14

Ketika diperhadapkan dengan pernyataan rasul Paulus, "Dia yang tidak mengenal dosa telah dibuat-Nya menjadi dosa karena kita" (2 Korintus 5:21)," Torrance berkata bahwa yang dimaksudkan dengan pernyataan tersebut bukanlah dalam arti Allah yang membuat Kristus menjadi seorang yang berdosa, tetapi membuat Kristus menjadi jalan substitusional (way of exchange, katallagē, atau substitution). ${ }^{15}$ Torrance menjelaskan bahwa dengan kebebasanNya, Kristus memasuki wilayah kemanusiaan yang telah rusak dan yang terhukum di bawah penghakiman Allah, dan mengambil semuanya itu menjadi milik-Nya. ${ }^{16}$

Berdasarkan penjelasan ini, maka bagi Torrance, mengambil kemanusiaan berdosa merupakan prakondisi Kristus untuk dapat menempuh jalan substitusional (vicarious way). Tanpa menjadi bagian dari manusia berdosa, Dia tidak dapat menjadi rekonsiliator atau penebus atau mediator. ${ }^{17}$ Bahkan tegasnya lagi, tanpa menjadi bagian dari manusia berdosa, kemanusiaan Kristus akan benar-benar doketis. ${ }^{18}$ Dengan kata lain, jika Allah di dalam Kristus tidak memasuki kondisi terhukum manusia di bawah murka Allah yang menyalanyala, Dia tidak dapat menjadi Juruselamat manusia.

14. Torrance, Incarnation, ed., Robert T. Walker, 205.

15. Torrance, Incarnation, ed., Robert T. Walker, 63.

16. Torrance, The Doctrine of Jesus Christ, 122

17. Torrance, The Doctrine of Jesus Christ, 122.

18. Torrance, The Doctrine of Jesus Christ, 122. 


\section{b. Kemanusiaan Kristus sebagai Respons Sempurna kepada} Allah

Pemikiran Torrance tentang Kemanusiaan-Substitusional Kristus ini mengikuti keyakinan Athanasius yang pernah mengatakan bahwa hanya Allah yang bisa menyelamatkan, tetapi Dia menyelamatkan sebagai manusia - Yesus Kristus adalah tindakan Allah, Allah bertindak secara pribadi dan segera sebagai manusia di dalam dan melalui Dia, dan dengan demikian sekaligus dalam cara yang ilahi dan manusia. ${ }^{19}$

Menurut Torrance, teologi patristik dan yang terutama dalam pemikiran Athanasius yang agung, menekankan banyak sekali fakta bahwa Kristus dibuat berdosa karena kita, menukar kekayaan-Nya dengan kemiskinan kita, kesempurnaan-Nya untuk ketidaksempurnaan kita, ketidakrusakan-Nya untuk kerusakan kita, kehidupan kekal-Nya untuk kefanaan kita. ${ }^{20}$ Kristus mengambil dari Maria tubuh yang rusak dan fana agar Dia dapat mengambil dosa kita, menghakimi dan mengutuknya dalam daging, dan dengan demikian mengambil sifat manusiawi kita seperti yang kita miliki di dunia yang telah jatuh ini sehingga Dia dapat menyembuhkan, menguduskan, dan menebus. ${ }^{21}$

19. Torrance F. Torrance, The Trinitarian Faith: The Evangelical Theology of Ancient Catholic Church (London: T \& T Clark, 1988), 149.

20. Torrance, Incarnation, ed., Robert T. Walker, 62.

21. Torrance, Incarnation, ed., Robert T. Walker, 62. 
Anak Allah yang berinkarnasi memperlihatkan dengan jelas sebuah pelayanan ganda (twofold ministry), ${ }^{22}$ di mana Kristus menjadi perantara hal-hal dari Allah kepada manusia (Godward movement) dan hal-hal dari manusia kepada Allah (manward movement). Pelayanan ganda Kristus, yaitu gerakan sisi Allah dan sisi manusia tidak boleh dilihat sebagai dua hal yang terpisah, melainkan dilihat sebagai keseluruhan yang muncul dari kesatuan pribadi Kristus sebagai Allah-manusia. ${ }^{23}$ Meski demikian, Torrance menitikberatkan pada sisi manusia kepada Allah ketika berbicara tentang Kemanusiaan-Substitusional Kristus. Torrance menjelaskan arti Substitusional (vicarious) sebagai "standing in our place" (Lat, vicarious, substitute). Kristus dalam kemanusiaan-Nya berdiri di tempat kita dan mewakili kita, dan dari sini muncul istilah 'Kemanusiaan-Substitusional' Kristus, di mana kemanusiaan Kristus mengambil tempat kita dan mewakili kita, sehingga apa yang benar tentang Dia ialah benar tentang kita, dan apa yang Dia lakukan dalam kemanusiaan-Nya (kita) adalah milik kita. ${ }^{24}$

Torrance meletakkan doktrin Kemanusiaan-Substitusional Kristus dalam bingkai relasi kovenan Allah dan bangsa Israel dalam Perjanjian Lama, ${ }^{25}$ di mana Allah dengan sabar dan berbelas kasih

22. Torrance, The Trinitarian Faith, 149.

23. Thomas F. Torrance, The Mediation of Christ (Colorado Springs: Helmers \& Howard, 1992), 73.

24. Torrance, Incarnation, ed., Robert T. Walker, 205.

25. Torrance menyoroti relasi Kovenan dalam Perjanjian Lama ketika Allah berbicara di hadapan segenap bangsa Israel, "Aku adalah Allah yang Mahakuasa; berjalan di depanku dan jadilah sempurna. 'Aku akan 
ketika Dia berinteraksi serta berelasi dengan bangsa Israel. Torrance melihat motif yang jelas dalam relasi kovenan Allah dengan bangsa Israel, dengan apa yang ia sebut sebagai respons kovenan ( $a$ covenanted way of response). Torrance mendefinisikan motif kovenan ini sebagai, Allah yang mendirikan dan memelihara umatNya dengan cara yang sepihak (unilateral way), dan sebagai kasih karunia semata, Dia dengan bebas menyediakan suatu jalan respons kovenan untuk meresponi Dia, sebuah cara substitusi di mana perjanjian dapat digenapi di tengah-tengah mereka dan atas nama mereka. ${ }^{26}$ Artinya, Allah adalah pihak satu-satunya yang dapat menyediakan jalan bagi Israel untuk mendekat kepada-Nya. Jalan tersebut dinyatakan oleh Allah dengan rinci melalui ketetapan ibadah bangsa Israel, agar melalui itu semua bangsa Israel dapat berespons dalam iman, ketaatan dan ibadah kepada Allah. ${ }^{27}$ Kovenan Allah dan bangsa Israel memberikan sebuah kesaksian bahwa hanya Allah

berjalan di antara kamu, dan menjadi Allahmu dan kamu akan menjadi bangsaku. 'Aku kudus, jadilah kamu kudus. 'Aku akan menjadi Bapa-Nya, dan dia akan menjadi anakku.'" Torrance, The Mediation of Christ, 73-74.

26. Torrance memberikan contoh kisah kemunculan motif tersebut. Ketika Allah menyediakan kurban yang menggantikan apa yang terbaik dari pihak manusia pikir dapat berikan dalam kisah Abraham mempersembahkan Ishak. Motif tersebut semakin jelas pada kisah Allah dan Israel di gunung Sinai. Allah mengetahui bahwa Israel tidak dapat memenuhi ketetapan-ketetapan kovenan, dan tidak dapat hidup kudus seperti diri-Nya adalah kudus. Israel juga tidak akan dapat mendekat kepada Allah dan menyembah-Nya sebagaimana mestinya. Tetapi Allah menyediakan jalan agar bangsa Israel dapat hidup di dalam kovenan Allah. Torrance, The Mediation of Christ, 74.

27. Torrance, The Mediation of Christ, 75. 
sendiri yang dapat menghilangkan rasa bersalah, mengampuni dosa, dan membawa pendamaian antara diri-Nya dengan umat-Nya. ${ }^{28}$

Perwujudan dan mediasi kovenan dalam Perjanjian Lama, menurut Torrance, sangat tergambarkan melalui konsepsi tentang hamba Allah. Torrance mengungkapkan bahwa nubuatan Yesaya, khususnya figur perantara dan keimaman Musa dan Harun yang memberikan gagasan tentang pembawa rasa bersalah dan pengorbanan untuk dosa diungkapkan untuk memberikan petunjuk interpretatif pada peran syafaat dan peran substitusional dari seorang hamba dalam penebusan umat Allah. ${ }^{29}$ Gambaran Hamba Allah dalam nubuatan Yesaya, menurut Torrance, dibayangkan dalam peran mesianik, sebagai mediator sekaligus kurban, sebagai imam sekaligus kurban, semua hal ini terkombinasi sebagai representasi dan substitusional. ${ }^{30}$ Dalam proses penyataan Allah kepada bangsa Israel, nubuatan Hamba Allah ini tergenapi dan terwujud dalam Yesus Kristus dan menginaugurasi kovenan yang baru.

Torrance melihat Yesus Kristus sebagai pribadi yang menghadirkan secara penuh aspek dan peran sebagai Hamba Allah. Torrance menyatakan bahwa ketika kita membuka halaman-halaman dalam Perjanjian Baru, kita akan menemukan bahwa Yesus Kristus dikenali dan diperlihatkan baik sebagai Hamba Allah dan sebagai Penebus ilahi yang telah datang untuk menanggung kesalahan,

28. Torrance, The Mediation of Christ, 75.

29. Torrance, The Mediation of Christ, 75.

30. Torrance, The Mediation of Christ, 76. 
pelanggaran dan kesalahan umat-Nya, namun bukan hanya untuk Israel tetapi untuk seluruh dunia. ${ }^{31}$ Inilah, menurut Torrance, merupakan inti dari Injil. Sebagai Anak Bapa yang berinkarnasi, Yesus Kristus diutus untuk memenuhi peran-Nya baik sebagai imam maupun sebagai kurban. ${ }^{32}$ Semua ini dikerjakan-Nya agar Kristus dapat mempersembahkan kita kepada Bapa-Nya, sebagai orangorang yang telah Dia tebus, dikuduskan dan disempurnakan selamalamanya di dalam diri-Nya. ${ }^{33}$ Dengan kata lain, Yesus Kristus menetapkan dalam kemanusiaan-Nya sendiri sebagai pemenuhan jalan substitusi respons manusia terhadap Allah yang dijanjikan di bawah perjanjian lama, tetapi sekarang atas dasar penebusan pengorbanan diri-Nya sekali untuk semua yang dipersembahkan, ini adalah jalan substitusi respons yang tersedia untuk semua umat manusia. $^{34}$

Motif respons terhadap kovenan dalam Perjanjian Lama telah digenapkan di dalam Kristus, yang telah memenuhi kovenan dari sisi Allah sekaligus sisi manusia. Oleh karena itu, Torrance memandang kemanusiaan Kristus sebagai respons sempurna manusia kepada Allah yang mengatasnamakan (on behalf of) kemanusiaan berdosa. ${ }^{35}$ Kristus menjadi true word dan true speech manusia kepada Allah. Di dalam dan melalui diri Kristus,

31. Torrance, The Mediation of Christ, 76.

32. Torrance, The Mediation of Christ, 76.

33. Torrance, The Mediation of Christ, 76.

34. Torrance, The Mediation of Christ, 76.

35. Torrance, The Mediation of Christ, 78. 
kemanusiaan, pemahaman, perkataan manusia berdosa diangkat, disucikan, dan dikuduskan, dan ditujukan kepada Allah Bapa bagi manusia berdosa. ${ }^{36}$

Di tengah anggapan umum yang hanya menekankan peristiwa kematian Kristus sebagai momen terpenting substitusional Kristus (vicarious death of Christ), ${ }^{37}$ Torrance justru memperluas konteks momen substitusional dalam keseluruhan kehidupan Kristus di dunia. Hal ini dikonfirmasi juga oleh Christian D. Kettler dalam bukunya The God Who Believes, bahwa sifat dari aktivitas rekonsiliasi Kristus tidak tercapai hanya dalam beberapa jam la digantung di kayu salib, tetapi mencakup keseluruhan hidup-Nya. ${ }^{38}$ Dengan mengikuti pemikiran para teolog konsili Nicea, Torrance menjelaskan bahwa rekonsiliasi dalam penebusan Kristus harus dilihat dalam cakupan seluruh kehidupan inkarnasi Allah kita, mulai dari buaian hingga kuburan-Nya, di mana sebagai salah satu dari kita dan satu dengan kita, Dia berbagi semua pengalaman kita, mengatasi ketidaktaatan kita melalui ketaatan-Nya dan menguduskan setiap tahap kehidupan manusia, dan dengan demikian menghidupkan dan memulihkan kemanusiaan kita untuk persekutuan dengan Allah. ${ }^{39}$ Dia menguduskan diri-Nya demi kepentingan kita agar kita dapat

36. Torrance, The Mediation of Christ, 78.

37. Thomas F. Torrance, 'Preaching Jesus Christ,' dalam A Passion for Christ: The Vision that Ignites Ministry, ed., Gerrit Dawson dan Jack Stein (Eugene: Wipf \& Stock, 2010), 24.

38. Christian D. Kettler, The God Who Believes: Faith, Doubt, and the Vicarious Humanity of Christ (Eugene, Cascade Books, 2005), 5.

39. Torrance, The Trinitarian Faith, 166-167. 
dikuduskan di dalam-Nya. Pengudusan diri imamat dan persembahan diri Kristus di sepanjang hidup-Nya di dunia harus dilihat sebagai bagian esensial terdalam dari mediasi penebusan yang dipenuhi-Nya di antara Allah dan umat manusia. ${ }^{40}$

Kristus bertindak atas nama kemanusiaan orang percaya yang berdosa melalui sepanjang hidup-Nya yang taat. Kristus memulihkan kemanusiaan orang percaya yang telah jatuh menjadi respons sempurna kepada Allah Bapa dan memulihkan persekutuan antara mereka dengan Allah. Kristus mengambil tempat, menjadi perantara, menggantikan diri-Nya bagi orang percaya, dan merealisasikan penebusan yang tidak dapat mereka lakukan.

Pemikiran Torrance ini juga membawa pada implikasi cara memandang dampak penebusan Kristus pada keselamatan orang percaya. Torrance melihat keselamatan yang dikerjakan Kristus melampaui pandangan keselamatan yang bersifat eksternal/forensik (interpretasi dominan tentang penebusan dalam Kekristenan Barat, bahkan kalangan Injili Konservatif). ${ }^{41}$ Dalam Kekristenan Barat, penebusan cenderung ditafsirkan hampir secara eksklusif dalam hal hubungan forensik eksternal sebagai transaksi yudisial dalam pemindahan hukuman dosa dari pendosa ke penanggung dosa. ${ }^{42}$ Mengenai hal ini, Torrance secara jelas mengatakan bahwa jika

40. Torrance, The Trinitarian Faith, 167.

41. Torrance mengkritik sekaligus melampaui teori penebusan forensik. Lih. Alexandra S. Radcliff, The Claim of Humanity in Christ: Salvation and Sanctification in the Theology of T. F. and J. B. Torrance (United Kingdom, James Clarke \& Co, 2017), 50-51.

42. Torrance, The Mediation of Christ, 40. 
inkarnasi tidak dianggap sebagai Anak Allah yang menembus dan mengambil alih kodrat manusiawi kita yang terasing, jatuh, dan berdosa, maka pendamaian dan rekonsiliasi yang menguduskan hanya dapat dipahami dalam istilah hubungan eksternal antara Yesus Kristus dan orang-orang berdosa. ${ }^{43}$

Pertama-tama, menurut Torrance, keselamatan orang percaya bukan hanya semata-mata dinyatakan benar di hadapan Allah, tetapi juga memberi dampak nyata pada kedalaman ontologis (ontological depth) diri seorang yang diselamatkan. ${ }^{44}$ Torrance menggambarkan apa yang dimaksudkan dengan kedalaman ontologis,

From his birth to his death and resurrection on our behalf he sanctified what he assumed through his own selfconsecration as incarnate Son to the Father, and in sanctifying it brought the divine judgment to bear directly upon our human nature both in the holy life he lived and in the holy death he died in atoning and reconciling sacrifice before God. That was a vicarious activity which was brought to its triumphant fulfillment and which received the verdict of the Father's complete approval in the resurrection of Jesus as God's beloved Son from the dead and in the rebirth of our humanity in him. ${ }^{45}$

Melalui kehidupan, kematian, serta kebangkitan-Nya Kristus masuk ke kedalaman ontologis kejahatan dan pelanggaran manusia dan

43. Torrance, The Mediation of Christ, 40.

44. Torrance, The Mediation of Christ, 41.

45. Torrance, The Mediation of Christ, 41. 
mengambil semuanya untuk ditebus, dan memberikan dampak restoratif pada kemanusiaan orang percaya. Maka dapat dipahami bahwa penebusan Kristus bukan hanya membawa pengampunan bagi dosa orang percaya, tetapi juga melahirkan kembali seluruh keberadaan diri orang percaya tersebut kepada kehidupan baru sebagai anak Allah. Di sisi lain, relasi ontologis orang percaya dengan Kristus memanggil orang percaya untuk berpartisipasi di dalam respons sempurna kemanusiaan Kristus. Dalam hal ini, Alexandra S. Redcliff mengatakan, "the believer does not apply what Christ accomplished; the believer participates in what Christ has accomplished." 46 Jadi, pertama-pertama, Kristus telah menggenapkan sepenuhnya bagi orang percaya, lalu orang percaya hanya berpartisipasi di dalam-Nya. Partisipasi orang percaya di dalam Kristus dimungkinkan hanya karena kuasa Roh Kudus. ${ }^{47}$

\section{Kemanusiaan-Substitusional Kristus dalam Iman, Pertobatan, dan Ibadah Orang Percaya}

Seperti yang telah disinggung dalam bagian sebelumnya, pemikiran Torrance ini menyangkal bahwa kemanusiaan Kristus hanya berperan sebagai instrumen penebusan saja, sehingga tidak ada pengaruh apa pun terkait kemanusiaan Kristus dengan

46. Radcliff, The Claim of Humanity in Christ, $\mathrm{x}$.

47. Bagi Radcliff, pengertian partisipasi seperti ini dapat menghindari dari pengertian partisipasi semi-pelagianisme di mana manusia turut andil usaha dalam keselamatan yang dikerjakan Allah. Radcliff, The Claim of Humanity in Christ, $\mathrm{x}$. 
pergumulan mendasar orang percaya sebagai manusia. Sebaliknya Torrance membuktikan bahwa jika penebusan Kristus dilihat secara utuh dalam seluruh momen kehidupan Kristus sebagai manusia, maka hal itu sungguh membawa dampak fundamental pada kehidupan orang percaya. Karena itu dalam bagian ini, penulis menunjukkan pemikiran Torrance menyentuh tiga aspek kehidupan orang percaya, yaitu iman, pertobatan dan ibadah.

- Iman

Iman atau percaya seringkali dilihat sebagai tindakan manusia. Memang dalam Injil terdapat seruan panggilan untuk percaya kepada Allah, atau pernyataan Kristus sendiri yang mengatakan, "imanmu telah menyelamatkan engkau" (Luk. 17:19). Akan tetapi menjadi sebuah kesalahpahaman besar jika iman atau percaya dipandang sebagai tindakan otonom, yang independen dan berdasarkan apa yang manusia dapat lakukan dari dirinya sendiri. ${ }^{48}$ Iman pada diri manusia seringkali rentan, goyah, pasang-surut, tidak konsisten, dan oleh karena itu iman tidak dapat berangkat dari diri manusia.

Iman harus diletakkan pada tempat yang tepat dalam "relasi kutub" antara Allah dan manusia, suatu relasi yang diaktualisasikan dalam Kristus, yang dengan-Nya manusia dipersatukan bersama untuk berbagi dalam iman-Nya dan kesetiaan-Nya. ${ }^{49}$ Dengan kata

48. Torrance, The Mediation of Christ, 82.

49. Torrance, The Mediation of Christ, 83-84. 
lain, melalui inkarnasi dan penebusan Kristus, iman manusia terlibat dengan iman-Nya. Berdasarkan kerangka kerja interpretatif Kemanusiaan-Substitusional Kristus, Torrance memaknai iman sebagai partisipasi kita dalam iman Kristus (our union with His faith). Torrance mengatakan, "we must think of Jesus Christ as believing, trusting and having faith in God the Father on our behalf and in our place." 50

Kristus adalah dasar dari iman orang percaya. Seperti yang diyakini oleh Torrance bahwa Kristus sebagai the author and finisher of our faith. ${ }^{51} \mathrm{Hal}$ ini tentu mendekonstruksi pemahaman tentang iman yang berlandaskan $50 \%$ apa yang telah dikerjakan oleh Allah dan $50 \%$ bagian manusia untuk menanggapi hal tersebut. ${ }^{52}$

50. Torrance memberikan contoh pengalaman iman Petrus, "kita dapat melihat gambaran ini pada hubungan Petrus dan Yesus. Yesus memegang Petrus dan tidak akan membiarkannya pergi di tengah ketidaksetiaannya. Anda akan ingat bagaimana, dalam perjamuan malam di mana Yesus menetapkan perjanjian baru dengan para murid-Nya di dalam tubuh dan darah-Nya untuk pembebasan dosa, Dia memberi tahu Petrus bahwa ia akan menyangkalnya tiga kali, dan kemudian menambahkan: 'Aku sudah berdoa untukmu agar imanmu tidak gagal.' Pada kenyataannya Petrus gagal, tetapi melalui kegagalan yang menakutkan itu iman Petrus dipulihkan, distabilkan dan diperkuat dalam pelukan kesetiaan Yesus yang teguh. Di atas batu karang iman itulah Gereja dibangun. "Torrance, The Mediation of Christ, 83.

51. Torrance, The Mediation of Christ, 84.

52. Dalam wawancaranya mengenai hubungan kemanusiaan Kristus dengan iman, Kettler mengatakan, "We often think of faith and belief in terms of something that we do. Often it that 'grace' is what God did. He did $50 \%$ of it, now it's up to us to have the faith part, the belief part." Christian D. Kettler, "The Importance of Jesus's Humanity," diakses 28 Mei 2020, https://learn.gcs.edu/mod/page/view.php?id=4372. 
Sebaliknya iman dipahami sebagai sesuatu hal yang sepenuhnya dikerjakan oleh Allah dalam Kristus, baik sisi Allah maupun sisi manusia. Karena itu hanya kepada Kristus sajalah, orang percaya menggantungkan imannya dari permulaan sampai akhir hidupnya.

Pergeseran paradigma dalam melihat iman ini sangat memengaruhi cara menanggapi pergumulan keraguan iman dalam diri seseorang. Seringkali keraguan iman seseorang ditanggapi dengan sebuah jawaban motivasi untuk mendorong orang tersebut lebih percaya lagi kepada Allah. Asumsi di balik jawaban tersebut terletak pada pemahaman dasar bahwa orang tersebut kurang beriman, maka dari itu harus ditambahkan lagi imannya. Model tanggapan terhadap pergumulan keraguan iman seperti ini sangat antroposentris, yang hanya berpusat pada apa yang manusia dapat capai dalam kehidupan imannya. Ditambah lagi iman manusia yang gampang sekali datang dan pergi, goyah dan rentan, maka pendekatan seperti ini bukanlah jawaban yang tepat bagi seseorang yang bergumul dengan masalah keraguan.

Dalam sebuah wawancara mengenai signifikansi kemanusiaan Kristus, Kettler memberikan pendekatan dari perspektif Kemanusiaan-Substitusional Kristus, kepada seseorang yang sedang bergumul dalam keraguan. Ketika ia sedang menghibur seseorang yang ragu, maka ia akan mengatakan, "Pandanglah Yesus, pandanglah iman-Nya. Anda mungkin merasa tidak setia kepada-Nya saat ini. Mungkin saat ini anda merasa sulit, dan tidak mungkin untuk percaya. Tetapi pandanglah iman-Nya, untuk menopang anda, 
mendukung Anda di saat-saat penuh keraguan ini." ${ }^{53}$ Kettler memperlihatkan bahwa ajakan seperti ini adalah ajakan yang lebih tepat, supaya orang yang sedang tersesat dalam keraguannya diarahkan kembali memandang pada Kristus dan meletakkan imannya dalam iman Kristus.

\section{- Pertobatan}

Kitab Injil juga berisi seruan-seruan pertobatan sebagai keputusan pribadi oleh orang percaya kepada Allah. Akan tetapi, lagilagi Torrance juga mengingatkan bahwa orang percaya harus melihat Yesus Kristus telah menggantikan mereka pada titik pertobatan. Jika tidak, Torrance menegaskan bahwa orang percaya menjadikan penebusan-Nya sebagai sesuatu yang parsial atau tidak utuh, dengan demikian mengecilkan signifikansi penyelamatan Kristus. ${ }^{54}$ Torrance memakai kisah perumpamaan anak yang hilang untuk menjelaskan bagian ini. Torrance menyamakan kemanusiaan yang telah jatuh dengan figur anak yang hilang, yang melarikan diri dari ayahnya ke "negeri yang jauh" (Luk. 15:11-32). Dengan menjadikan diri-Nya satu dengan manusia yang telah jatuh dan terasing ketika melarikan diri dari Bapa, Yesus Kristus "membalikkan arahnya dan mengubahnya kembali dalam kepatuhan dan iman dan kasih kepada Allah Bapa." ${ }^{25}$

53. Kettler, "The Importance of Jesus's Humanity," diakses 28 Mei 2020, https://learn.gcs.edu/mod/page/view.php?id=4372.

54. Torrance, The Mediation of Christ, 84.

55. Torrance, The Mediation of Christ, 84. 
Apa yang tidak dapat manusia kerjakan, dikerjakan oleh Kristus bagi manusia itu sendiri. Sebab manusia pada dirinya sendiri tidak mampu membuat respons cinta yang sempurna, tindakan penyesalan yang sempurna, dan penyerahan diri yang sempurna. Kristus adalah Pertobatan-Substitusional (The Vicarious Repentance) bagi manusia. Dalam Kristus, sang Anak Allah yang berinkarnasi, terlihat bagaimana Allah memberikan diri-Nya kepada umat manusia dalam pengampunan tanpa syarat, dan pada saat yang sama Yesus, sebagai wakil kemanusiaan, dalam kehidupan penuh ketaatan-Nya telah menjadi respons sempurna pertobatan yang menggantikan manusia berdosa kepada Allah.

Torrance juga menyoroti kisah baptisan Kristus oleh Yohanes Pembaptis sebagai momen baptisan pertobatan-substitusional (baptism of vicarious repentance) bagi manusia berdosa, yang Dia bawa sampai akhir di kayu salib. ${ }^{56}$ Kristus menggenggam manusia, bahkan di kedalaman pikiran manusia yang jatuh, yang telah diasingkan dari Allah, dan mengubah mereka dari dalam dan dari bawah dalam metanoia yang radikal dan lengkap, mengubah pikiran duniawi manusia menjadi pikiran spiritual. ${ }^{57}$ Karena itu, pertobatan bukanlah semata-mata dilihat sebagai tindakan orang percaya kepada Allah, melainkan tindakan Kristus Yesus yang telah mengerjakan pertobatan sepenuhnya bagi orang percaya di hadapan Allah Bapa. Torrance menjelaskan bahwa kelahiran baru kita,

56. Torrance, The Mediation of Christ, 85.

57. Torrance, The Mediation of Christ, 85. 
regenerasi kita, pertobatan kita, adalah apa yang telah terjadi di dalam Yesus Kristus sendiri, sehingga ketika kita berbicara tentang pertobatan atau regenerasi kita, kita mengacu pada keberbagian dalam pertobatan atau regenerasi kemanusiaan kita yang dibawa oleh Yesus dalam dan melalui diri-Nya sendiri demi kita. ${ }^{58}$

- Ibadah

Seperti yang telah disinggung dalam bagian sebelumnya, Torrance menekankan bahwa Kristus adalah pemenuhan dari respons kovenan dari seluruh ibadah bangsa Israel. Sehingga semua ibadah dan doa manusia kepada Allah didasarkan dan berpusat pada diri-Nya. ${ }^{59}$ Semua ini dilakukan oleh Kristus karena seluruh ibadah dan doa dari diri manusia sepenuhnya kotor di hadapan Allah. Hanya melalui Dia, dengan Dia, dan di dalam Dia, manusia dapat mendekat kepada Allah, dengan iman manusia yang tidak dipenuhi dengan persembahan lain selain dari apa yang telah Dia lakukan atas nama manusia dan dengan demikian menggantikan manusia untuk selamanya. ${ }^{60}$ Dengan jalan seperti ini, maka Kristus adalah Ibadah dan Doa-Substitusional (The Vicarious Worship and Prayer) bagi manusia. Artinya, Yesus Kristus mewujudkan diri-Nya dalam bentuk sebagai substitusi respons manusia kepada Allah, sehingga seluruh

58. Torrance, The Mediation of Christ, 86.

59. Torrance, The Mediation of Christ, 87.

60. Torrance, The Mediation of Christ, 87. 
ibadah dan doa mereka kepada Allah untuk selanjutnya berpusat pada diri-Nya. ${ }^{61}$

Pada umumnya ibadah dipandang semata-mata sebagai seperangkat aktivitas manusia: pergi ke gereja, menaikkan pujian, menaikkan doa, mendengarkan khotbah, dan memberi persembahan. Setelah semua hal ini dilakukan dan dipenuhi, seakanakan telah selesai pula tugas beribadah orang percaya. Pemahaman seperti ini sangat mengandalkan kekuatan manusia itu sendiri, dan semua berpusat pada apa yang manusia dapat berikan kepada Allah. Berdasarkan terang Kristus sebagai Ibadah dan doa-Substitusional, maka makna ibadah dan doa pertama-tama harus dilihat sebagai sebuah tindakan memberi ruang untuk kehadiran Kristus yang telah menjadi perantara, sehingga bersama Dia orang percaya berdoa dan beribadah, dan dengan cara seperti demikianlah Allah berkenan atas doa dan ibadah orang percaya. ${ }^{62}$

61. Torrance, The Mediation of Christ, 87.

62. Torrance menceritakan pengalaman doa pribadinya dalam konteks keyakinannya akan Kristus sebagai the vicarious worship and prayer, "Di penghujung hari ketika saya berlutut dan mengucapkan doa di malam hari, saya tahu bahwa tidak ada doa saya sendiri yang dapat saya ucapkan kepada Bapa surgawi secara layak, tetapi semua doa saya terkabul dalam nama Yesus Kristus saja saat saya tinggal dalam doa substitusional-Nya. Dengan kedamaian dan kegembiraan yang luar biasa saya memasukkan ke dalam mulut saya Doa Bapa Kami yang mengundang saya untuk berdoa melalui Yesus Kristus, dengan Dia dan di dalam Dia, kepada Allah Bapa, karena dalam doa itu kemalangan, kegoyahan, dan keberdosaan saya tidak diizinkan jatuh ke tanah tetapi diangkat dan dipersembahkan kepada Bapa dalam bentuk yang kudus dan berlaku selamanya. Pada saat yang sama, saya ingat bahwa Bapa telah berjanji untuk mengirimkan Roh dari anak-Nya, yang dimediasi melalui nama dan Kemanusiaan-Substitusional Yesus, ke dalam 
Jadi, ketika orang percaya menghadap kepada Allah, melakukan tindakan liturgi pengakuan dosa, penyembahan, dan ucapan syukur, itu bukan atas nama mereka sendiri, melainkan semata-mata berdasarkan apa yang telah dilakukan Kristus di tempat mereka atas nama mereka. Oleh sebab itu, nilai kelayakan ibadah dan doa tidak bergantung pada apa yang dapat dicapai oleh orang percaya, melainkan berdasarkan apa yang telah dikerjakan dan diselesaikan oleh Kristus. Allah tidak menerima orang percaya atas dasar hal berharga yang dipersembahkan oleh mereka kepada Allah. Tetapi semata-mata anugerah-Nya yang secara bebas menerima mereka di dalam Kristus, yang telah bertindak dari sisi kemanusiaan mereka, dan yang telah menjadi persembahan yang sempurna kepada Allah.

Kebenaran tentang Kristus sebagai Ibadah dan doaSubstitusional juga mengingatkan orang percaya dalam seluruh ibadah dan doanya kepada Allah, bahwa ada Pribadi yang selalu berada bersama mereka dan berdiri di antara (in between), yaitu Yesus Kristus. Bahkan dalam pergumulan orang percaya yang paling berat dan gelap sekalipun, ketika mereka tak mampu untuk berkatakata dalam doanya, Kristus melalui Roh Kudus berdoa untuk, dengan, di dalam mereka. James B. Torrance secara kreatif dan indah

hati kita, sambil menangis, Abba, Bapa; dan saya yakin bahwa sewaktu saya berdoa dalam nama Anak Terkasih Allah, saya tertangkap dengan semua kelemahan saya sendiri di dalam syafaat yang tidak dapat terartikulasi dari Roh Bapa yang kekal dan Anak, dan tidak ada apa pun di dunia ini atau di dunia yang akan datang, dapat memisahkan kita." Torrance, The Mediation of Christ, 88. 
menuangkan pemikiran teologis Kristus sebagai Imam Besar yang berdoa bagi orang percaya ke dalam himne yang dia ciptakan dengan diberi judul "I Know Not How to Pray,"

(Bait 1)

I know not how to pray, O Lord. So weak and frail am I. Lord Jesus to Your outstretched arms in love I daily fly: For You have prayed for me.

(Bait 2)

I know not how to pray, O Lord. O'erwhelmed by grief am I. Lord Jesus, in Your wondrous love. You hear my anxious cry, and ever pray for me.

(Bait 3)

I know not how to pray, O Lord. For, full tears and pain. I groan, yet in my soul I know. My cry is not in vain. $O$ teach me how to pray.

(Bait 4)

Although I know not how to pray, Your Spirit intercedes. Convincing me of pardoned sin. For me in love He pleads and teaches me to pray.

(Bait 5)

$\mathrm{O}$ take my worthless sighs and fears. And make prayers Your own. O put Your prayer within my lips. And lead me to God's throne, that I may love like you." ${ }^{63}$

\section{Penutup}

Penebusan Kristus tidak dapat dipersempit pada momen kematian-Nya, karena jika demikian maka orang percaya akan gagal untuk memahami keutuhan signifikansi seluruh pelayanan Kristus

63. Lihat partitur himne beserta seluruh baitnya dalam James B. Torrance, "I Know Not How to Pray", dalam A Passion for Christ: The Vision that Ignites Ministry, ed., Gerrit Dawson dan Jack Stein (Eugene: Wipf \& Stock, 2010), 53. 
dan kemanusiaan Kristus bagi keselamatan mereka. Penebusan Kristus bukan hanya perkara mengampuni dosa, tetapi merestorasi seluruh keberadaan diri orang percaya menjadi ciptaan baru di dalam Dia. Melalui terang Kemanusiaan-Substitusional Kristus, orang percaya diajak untuk selalu memiliki gairah hidup berpartisipasi ke dalam kehidupan Kristus yang telah mengubah seluruh aspek kemanusiaan berdosa mereka menjadi respons sempurna kepada Bapa. Kemanusiaan-Substitusional Kristus seharusnya menjadi dasar ontologis bagi kehidupan orang percaya, dalam hal iman, pertobatan, dan ibadah.

\section{Daftar Pustaka}

Kettler, Christian D. The God Who Believes: Faith, Doubt, and the Vicarious Humanity of Christ. Eugene, Cascade Books, 2005.

Monar, Paul D. Thomas F. Torrance: Theologian of the Trinity. England: Ashgate Publishing, 2009.

Radcliff, Alexandra S. The Claim of Humanity in Christ: Salvation and Sanctification in the Theology of T. F. and J. B. Torrance. United Kingdom, James Clarke \& Co, 2017.

Torrance, David W. "The Vicarious Humanity of Christ," Makalah ini disampaikan pada konferensi teologi T. F. Torrance yang diadakan pada November 2010 di Firbush, Loch Tay, Universitas Edinburgh.

Torrance, James B. "I Know Not How to Pray." Dalam A Passion for Christ: The Vision that Ignites Ministry. Diedit oleh Gerrit Dawson dan Jack Stein. Eugene: Wipf \& Stock, 2010.

Torrance, Thomas F. "Preaching Jesus Christ." Dalam A Passion for Christ: The Vision that Ignites Ministry. Diedit oleh Gerrit Dawson dan Jack Stein. Eugene: Wipf \& Stock, 2010. 
Torrance, Thomas F. Incarnation: The Person and Life of Christ. Diedit oleh Robert T. Walker. Downers Grove: InterVarsity Press, 2008.

Torrance, Thomas F. The Doctrine of Jesus Christ. Eugene: Wipf and Stock Publishers, 2002.

Torrance, Thomas F. The Mediation of Christ. Colorado Springs: Helmers \& Howard, 1992.

Torrance, Thomas F The Trinitarian Faith: The Evangelical Theology of Ancient Catholic Church. London: T \& T Clark, 1988.

\section{Website}

Kettler, Christian D. "The Importance of Jesus's Humanity." diakses 28 Mei 2020.

https://learn.gcs.edu/mod/page/view.php?id=4372 